\title{
O Solo de Django Reinhardt em Flèche d'Or
}

\author{
Laurent Cugny (Université Paris-Sorbonne, França) \\ Laurent.Cugny@paris-sorbonne.fr \\ Tradução de Fabiano Araújo (UFES, Vitória, ES) \\ armoniah@gmail.com
}

Resumo: Transcrição e análise do solo de Django Reinhardt na música Flèche d'Or, de sua autoria. Os aspectos estruturais e harmônicos desta obra, gravada em janeiro de 1952, revelam forte semelhança com Milestones de Miles Davis, gravada em 1958, que é a aceita como a primeira do jazz modal. 0 artigo apresenta, também, uma transcrição dos acentos e deslocamentos feitos pelo baterista Pierre Lemarchand, para demonstrar um erro de compasso que pode ser explicado pelo caráter inédito deste tipo de forma musical no jazz da época. A análise revela no solo de Django, uma abordagem outside tanto em termos harmônicos quanto rítmicos.

Palavras-chave: Django Reinhard e Miles Davis; história do bebop e jazz modal; solo de guitarra no jazz; jazz na França.

\section{Django Reinhardt's solo on Flèche d'Or}

\begin{abstract}
Transcription and analysis of Django Reinhardt's solo on his own composition, Flèche d'Or. The structural and harmonic aspects of this work, recorded in 1952, show great similarities with Milestones (1958) by Miles Davis, a wellknown work generally accepted as the first example of the so called modal jazz. This article also presents a transcription of the accents and displaced rhythms performed by the drummer Pierre Lemarchand, in order to demonstrate a measure mistake that could be caused by the recent novelty of this kind of musical form in jazz. The analysis of the solo reveals an "outside" approach by Django as far as the harmony and rhythm are concerned.
\end{abstract}

Keywords: Django Reinhardt and Miles Davis; history of bebop and modal jazz; jazz guitar solo, jazz in France.

\section{1 - Introdução}

Flèche d'Or, composição de Django Reinhardt, registrada no dia 30 de janeiro de 1952, nos estúdios da gravadora Decca, em Paris. Django na guitarra elétrica, é acompanhado por jovens e afiados músicos franceses da era bebop: Roger Guérin, trompete; Hubert Fol, sax alto; Raymond Fol, piano; Barney Spieler, contrabaixo acústico e Pierre Lemarchand, bateria.

A forma da composição é absolutamente original: tratase de um $A A B B A$, isto é, uma forma tradicional $A A B A$ com a ponte duplicada. Dentre os pouquíssimos exemplos de tal forma no repertório dos "jazzmen" o primeiro a ser lembrado será, sem dúvida, Milestones, de Miles Davis, que foi gravada pelo próprio trompetista seis anos depois de Flèche d'Or. São exemplos, também, Bridgehampton Strut, composta e arranjada por Gary McFarland para a orquestra de Gerry Mulligan, e gravada por este último em 1963; e Midnight Voyage, de Joey Calderazzo, que pode ser ouvida no disco Tales from the Hudson (1996), de Michael Brecker.

Outra característica desta composição é conter apenas um acorde por seção, Si menor $(B m)$, na Seção $A$, e Mi com sétima (E7), na Seção $B$. Trata-se, pois, seis anos antes de Milestones e sete antes de Kind of Blue, do que pode ser considerado como a primeira gravação de jazz "modal", no senso moderno do termo'. A gravação de uma composição com tais características colocaria, portanto, novos tipos de problemas aos músicos da época. Mais do que a estrutura com a ponte dupla, o que se apresenta como uma dificuldade é o fato de haver apenas um acorde por seção ao invés dos típicos encadeamentos harmônicos 
do jazz. Seria o desaparecimento dessa marca essencial que, como veremos, acarretará em um erro de execução, na verdade atribuído ao baterista, Pierre Lemarchand.

\section{2 - 0 erro de compasso em Flèche d'Or}

Conforme o que se espera de seu papel de baterista, Lemarchand marca claramente a estrutura do tema na exposição, como mostra o Ex.1, atacando com o bumbo o primeiro tempo de cada nova seção (c. 1,17$)$, e também a retomada do tema depois da ponte (c.33). Mas, como todo bom baterista de bebop, Lemarchand irá, em seguida, quebrar um pouco as marcações durante o solo de Django, lançando as famosas "bombas" que os conservadores tanto detestam, quer dizer, deslocando os ataques de bumbo para fora do tempo forte dos inícios das seções. (Ex.1)

Depois de marcar o primeiro tempo do início do solo (Ex.2), Pierre Lemarchand sublinha imediatamente um quarto tempo (c.41). No segundo $\boldsymbol{A}$, no c.49, já não é mais 0 primeiro, mas sim, o terceiro tempo que é marcado. Nada na primeira passagem do $\boldsymbol{B}$ (c.57), mas, no primeiro compasso do segundo $B$ (c.65), um terceiro tempo é novamente marcado. Nada no retorno do $\boldsymbol{A}$ (c.73), porém, um quarto tempo sobre o quinto compasso desta parte (c.77). (Ex.2)

No começo do segundo chorus (Ex.3), Lemarchand acompanha o riff de trompete e saxofone marcando o primeiro e quarto tempo do c.81 e do c.85, e depois somente o quarto tempo do c.88. Retomando o padrão tradicional, ele volta a marcar o primeiro tempo dos c.97 e 101 da ponte. No primeiro compasso da repetição da ponte (c.105), notamos um impasse. 0 que aconteceu por ali? Nos c. 109 e 111, Lemarchand marca os terceiros tempos. Teria ele, deixando-se levar pelo movimento, se confundido e tomado estes terceiros tempos como primeiros? Tanto é o que parece que ele acrescenta dois tempos nos últimos compassos da ponte deixando três colcheias no ar (c.112). Nota-se claramente a desestabilização produzida por todos nos primeiros compassos do último $\boldsymbol{A}$ (c.113 e 114). Mas o grupo se recupera rapidamente. 0 baterista marca o primeiro tempo do c.119. Não há mais ambiguidade, o tema pode ser retomado sem hiatos no c. $121^{2}$.
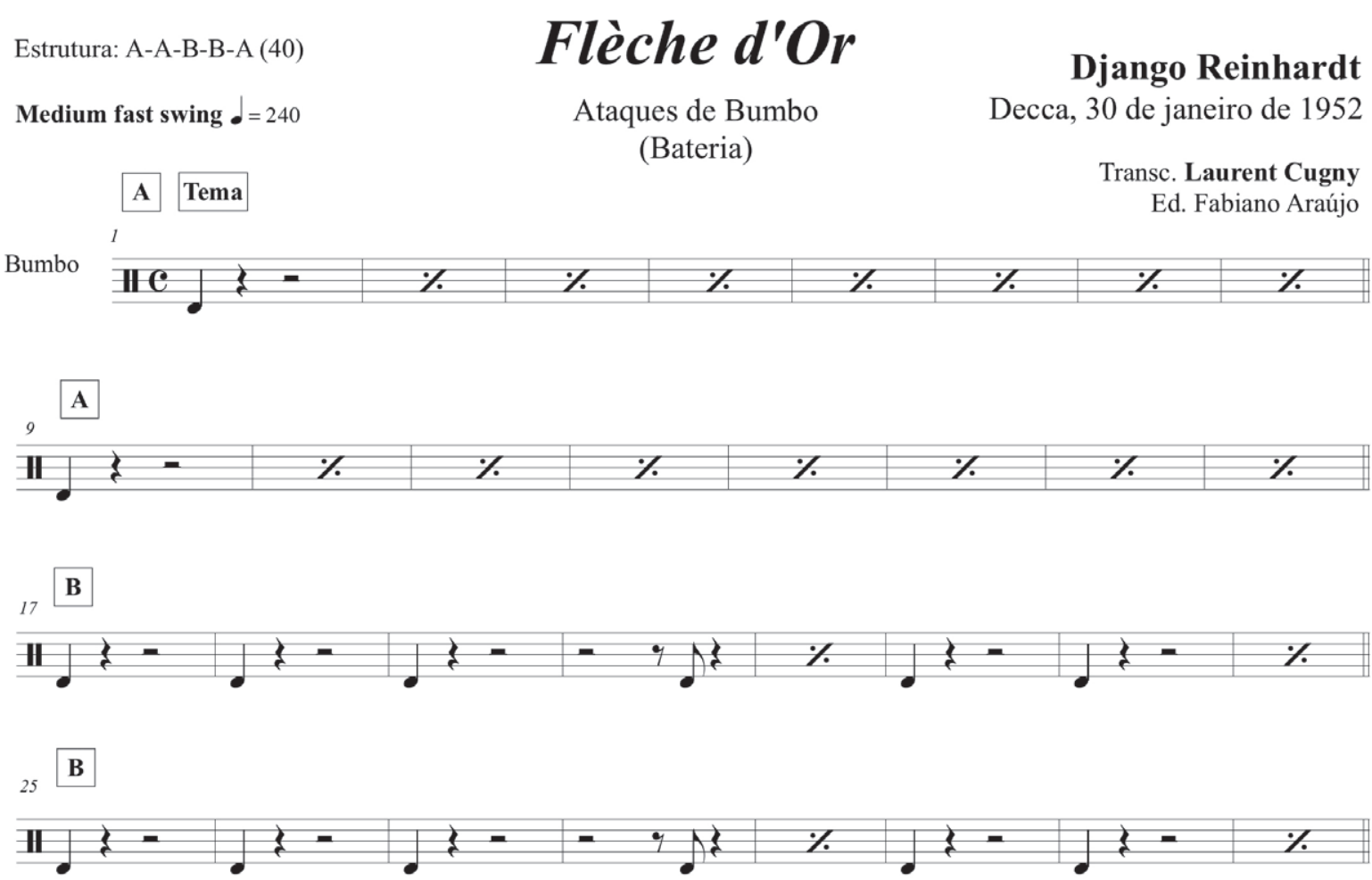

$33 \mathbf{A}$

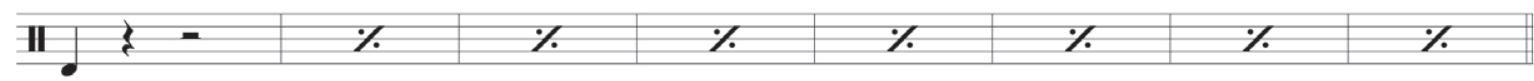

Ex.1 - Ataques de bumbo na exposição do tema de Flèche d'Or de Django Reinhardt. 
A Chorus 1
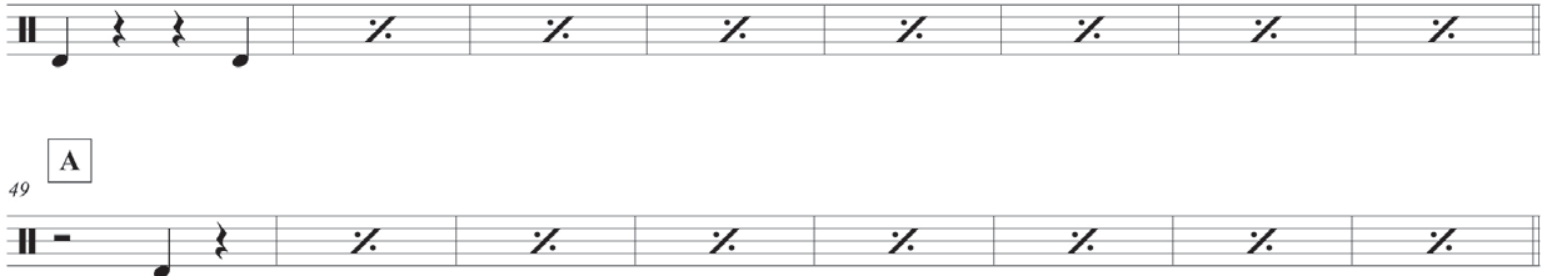

${ }_{57}$ B

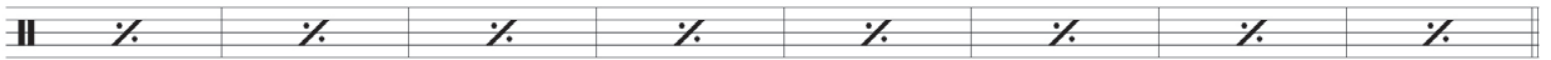

B

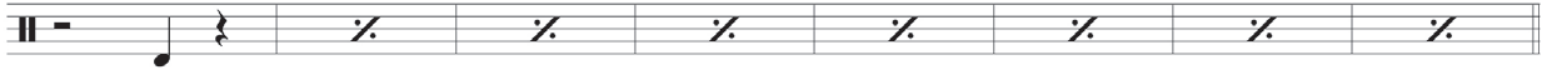

$\mathbf{A}$

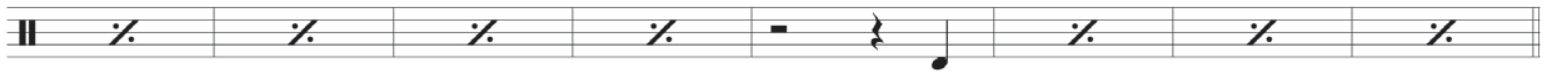

Ex.2 - Ataques deslocados de bumbo no primeiro chorus solo de Django em Flèche d'Or.
A Chorus 2
Flèche d'Or
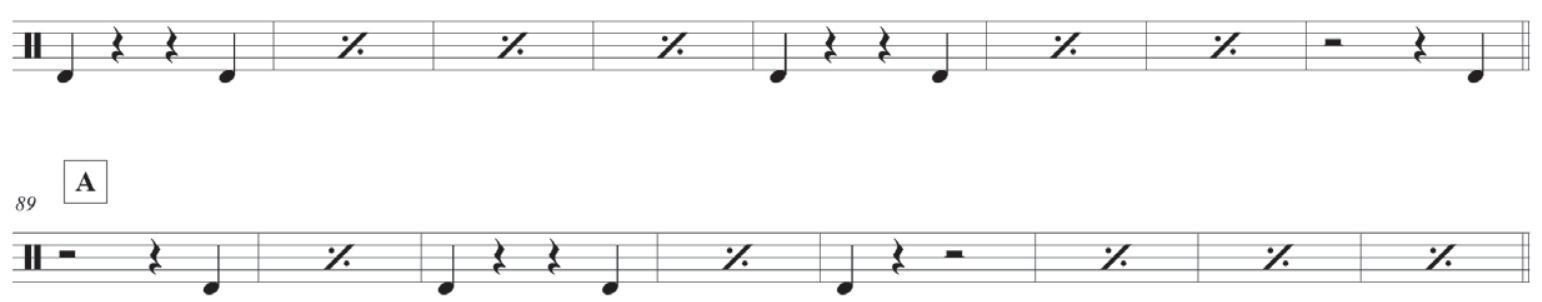

${ }_{97} \mathbf{B}$
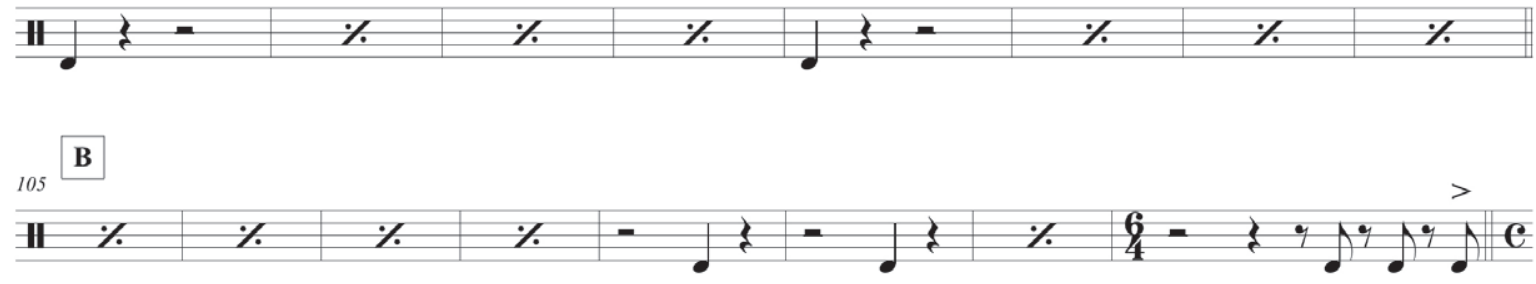
$\mathbf{A}$

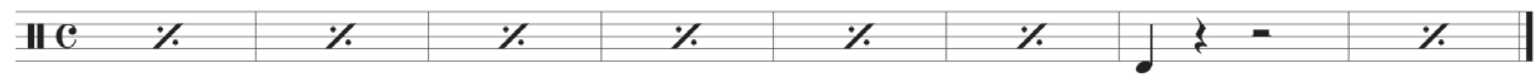

Ex.3 - Ataques deslocados de bumbo no segundo chorus do solo de Django em Flèche d'Or. 
0 objetivo desta análise não está, evidentemente, em apontar a insuficiência de um ou outro músico, mas em observar que não somente o bebop ainda era uma prática recente na época da gravação, mas, sobretudo, que os músicos - incluindo e talvez em maior medida, os bateristas - estavam habituados a seguir os encadeamentos harmônicos que Ihes indicavam ou confirmavam o desenrolar da estrutura. 0 fato de não haver mais que um acorde por seção elimina com certeza esta forma de percepção. Compreende-se, assim, que uma desestabilização possa ter ocorrido, até mesmo porque além desta ausência de encadeamentos harmônicos, havia uma anomalia de estrutura (o dobramento da ponte); e sobretudo, que esta tenha sido a primeiríssima vez que esses músicos (e talvez, até mesmo, que algum músico de jazz) estivessem diante deste tipo de dificuldade.

\section{3 - 0 solo de Django}

Django não se apresenta impecável no plano da técnica. Ele agarra em certas frases, particularmente no final (c.110-111), e certas notas parecem faltar, por exemplo, nos c.43-44, c.77 ou c.87. Mas, se este aspecto puramente técnico é ultrapassado, todo o solo se mostra de um nível superlativo e de uma inventividade fora do normal. A começar pelo som da guitarra elétrica. Django a toca de tal forma que Marcello Piras chegou a dizer que ele soa "como o papa Jimi Hendrix". Esta sonoridade é particularmente audivel na ponte da exposição do tema (e da reexposição no fim da peça) ${ }^{3}$ e, no solo, no início do segundo chorus (c. 81 e c.81 em diante).

E quanto a harmonia, o que pode-se dizer? Certamente andava-se sobre um terreno quase virgem, posto que, na época, havia pouca ou nenhuma referencia em matéria de improvisação sobre um único acorde. Notemos que esses acordes - Bm7 e E7 - são, inclusive, bem "guitarrísticos" (seriam um pouco mais difíceis para instrumentos de sopro). Não me parece adequado falar aqui de jazz modal ${ }^{4}$, pois Django não se prende a um único modo, e nem mesmo a vários, mas desafia uma fixação a uma escala, sem, no entanto, cair no atonalismo. Sobre a Seção $A$ (Ex.4), ouviremos com maior frequência, certamente, a escala de Si menor harmônico (com o Lá sustenido) e a de Si menor natural, porém, constantemente alteradas.

Assim começa seu solo sobre um Fá natural "urrante" (que pode-se ouvir como uma blue note) para fixarse, em seguida, sobre a menor harmônica. Porém, logo chega um Dó natural. 0 solo como um todo é um modelo do tipo "out" que um John Scofield não renegaria, sem dúvida. 0 efeito "out" é reforçado na mesma medida em que é preparado por trechos "in" em determinados momentos. Assim funciona o Dó natural do c. 44, e também o do c. 51. (Ex.4)

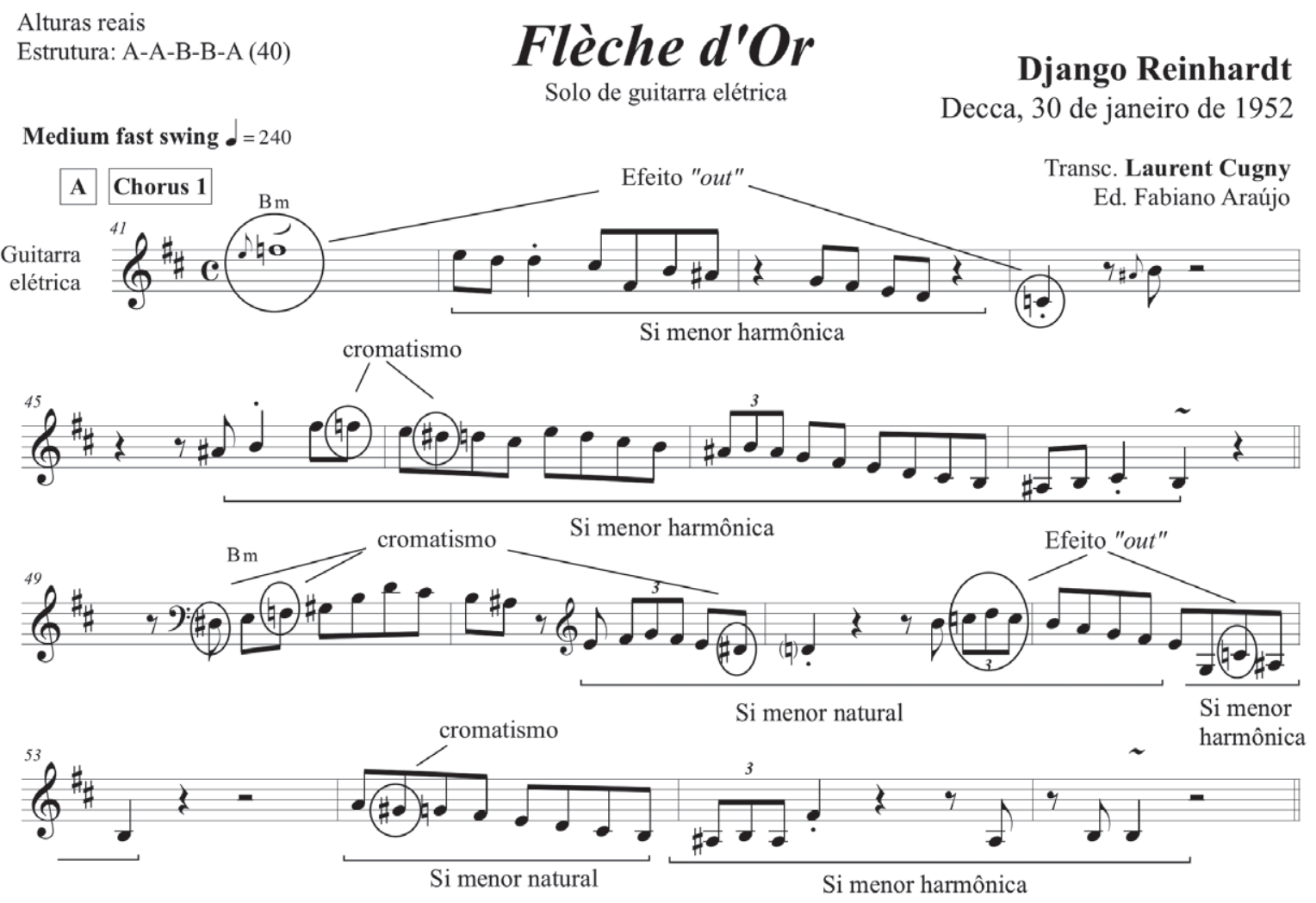

Ex.4 - Primeiro chorus do solo de Django em Flèche d'Or, Seção A, c.41-56. 
0 arpejo de Sol diminuto que parte do c.65 (Ex.5a) concluindo no Ré sustenido (c.66) soa então muito "fora" em relação à harmonia de $\mathrm{E7}$ precedente. Efeito inverso com o retorno imediato do arpejo de E9, por sua vez, bastante "dentro".

Seguindo esta lógica, o efeito se manifesta novamente no retorno da Seção $\boldsymbol{A}$ (Ex.5b): a harmonia de Bm é executada bem "in", unicamente com as notas do acorde perfeito (mesmo estando elas ornamentados) em um arpejo superposto culminando em um Dó e um Sol naturais triunfantes de dissonância (c.75). (Ex.5b)
Em toda a Seção $A$ do segundo chorus (Ex.6), Django toca bastante "in", sobretudo entre os c.89 e 92, antes de trabalhar durante os quatro compassos seguintes um Lá sustenido bem dissonante.

0 Ex.7 mostra que Django mantêm esta linha de improviso com um primeiro $B$ também muito dissonante antes de tocar os c. 105 a 108, bem consonante. Ele arrisca, enfim, uma figura realmente atonal nos c.109-110, mas agarra "guitarristicamente" (talvez, quem sabe, devido a esta proeza harmônica).
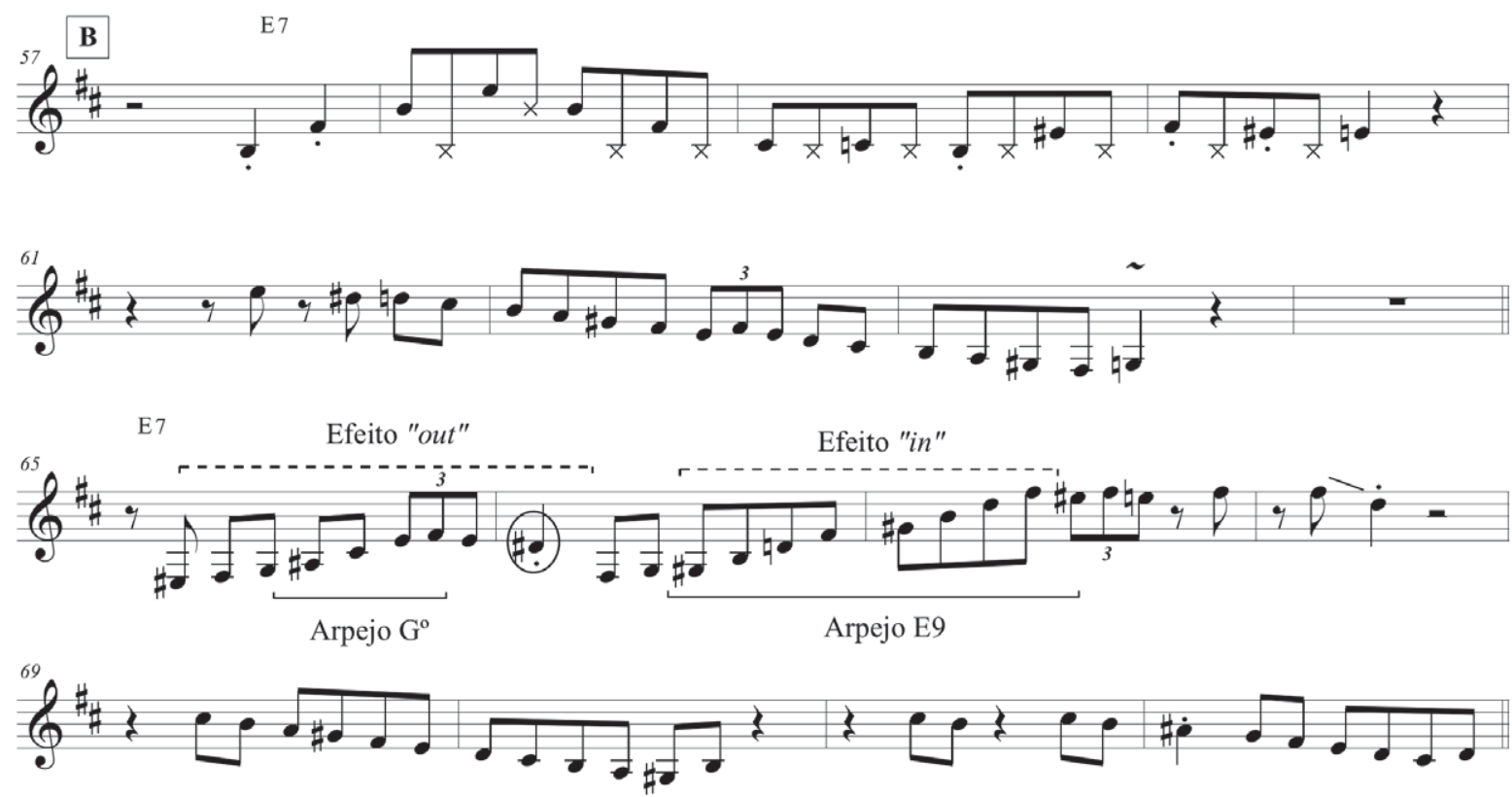

Ex.5a - Primeiro chorus do solo de Django em Flèche d'Or, Seção B, c.57-72.

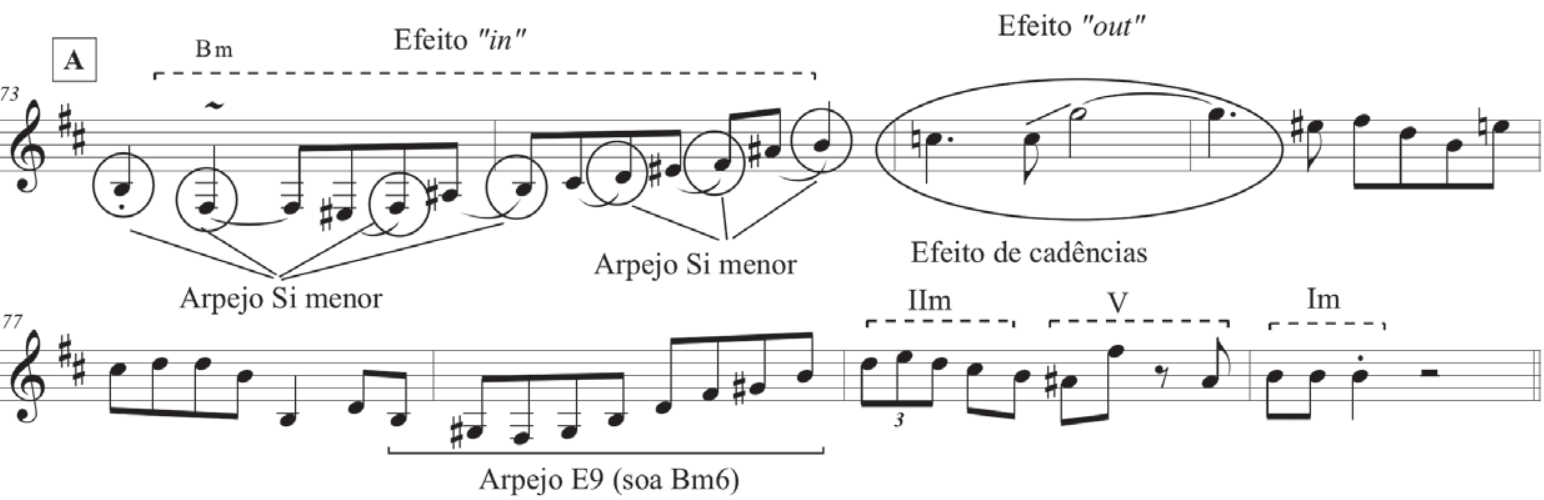

Ex.5b - Primeiro chorus do solo de Django em Flèche d'Or, Seção $A$, c.73-80. 

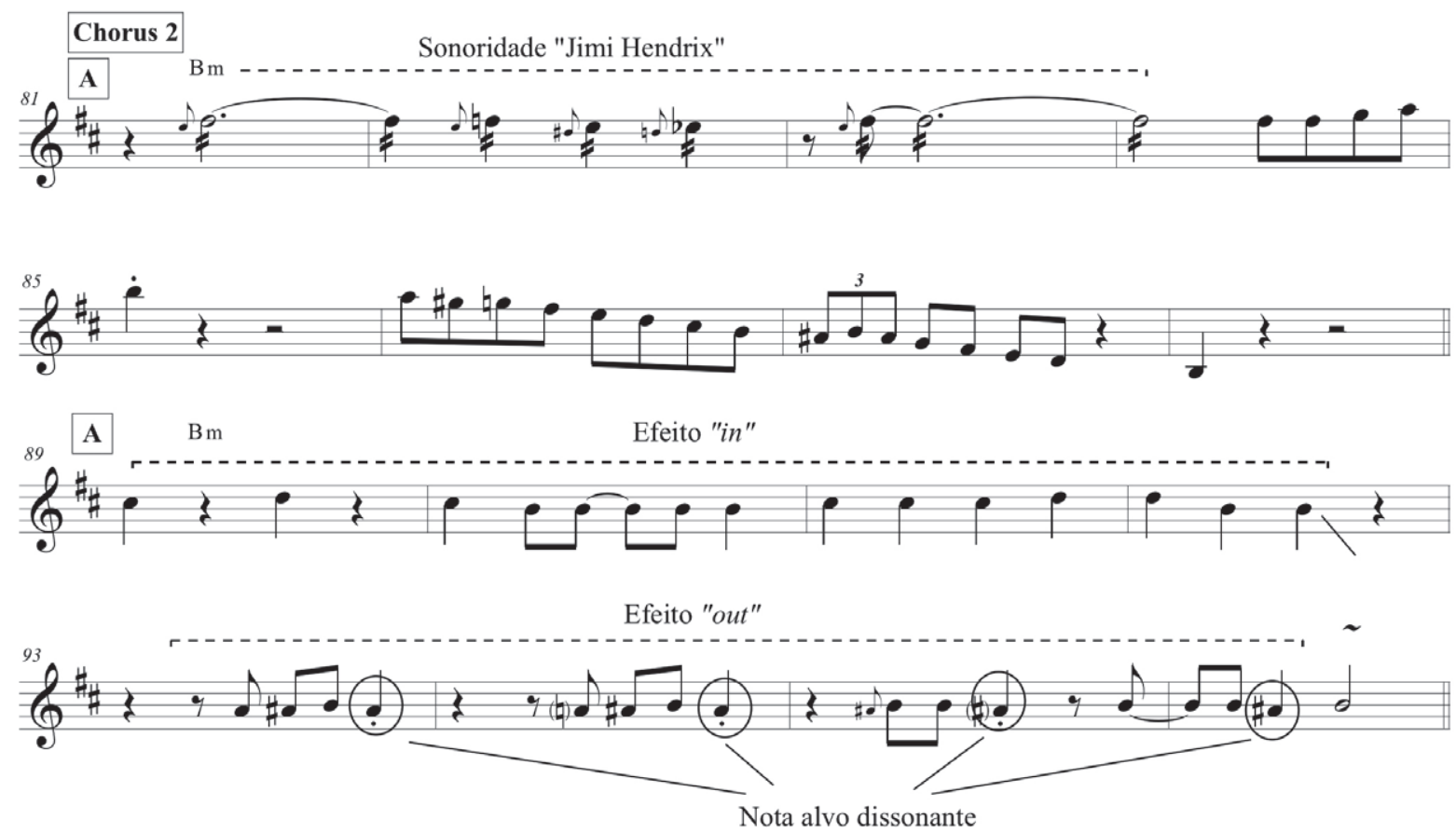

Ex.6 - Segundo chorus do solo de Django Flèche d'Or, Seção $A$, c.81-96

Notaremos, ainda, que Django toca o mesmo arpejo superposto de E9 nos c.66-67, na ponte do primeiro chorus (Ex.5a, mostrado acima) e nos c.107-108, no segundo chorus(Ex.7). Manifestamente, ele se presta a ter este arpejo sob os dedos e utilizá-lo também nas Seções $A$, nos c.78-79 (Ex.5b, mostrado acima) e nos c.117-118 (Ex.7), onde ele faz soar, desta vez, como um Bm6.

Django emprega, vez por outra, um procedimento que encontraremos também no Miles Davis modal. Tal procedimento consiste em tocar cadências mesmo que a seção rítmica permaneça parada em um mesmo acorde. Este é o caso, a meu ver, nos c.49-51 (Ex.8). Sobre o c.49, ele toca um arpejo que pode ser considerado um C\#7(b9) seguido de uma harmonia de F\#7(b9), no c.50, antes de tocar o Ré natural do acorde de Si menor no primeiro tempo do c.51: trata-se aqui de um movimento II-V-i. 0 mesmo tipo de coisa ocorre nos c.46-48, c.54-56 (Ex.8) e c.79-80 (Ex.5b, mostrado acima).

Também há o que dizer sobre o aspecto rítmico. Django se presta a vários exercícios de dissimetria (Ex.9), identificados particularmente nos c.93-97 e também nos c.101-104, que se destacam na medida em que se alternam, da mesma forma como percebido para a harmonia, com frases mais "in" ritmicamente (c.89-92, c.97-100).

Escutando tal obra-prima, parece absurdo quando Roger Paraboschi, que tocava com Django na época, confessa que para alguns jovens músicos da época, Django era ... quadrado ${ }^{5}$.

Agradecimentos: Andrew Homzy, Bill Kirchner, Roger Paraboschi, Marcello Piras, Lewis Porter e David Wild. Agradeço também a Les Cahiers du Jazz que gentilmente cedeu o direito de publicar este artigo em português a partir do original "Le solo de Django Reinhardt dans Flèche d'Or". In: Les Cahiers du jazz. Nouvelle série, n³, 2006, p.213-218. 

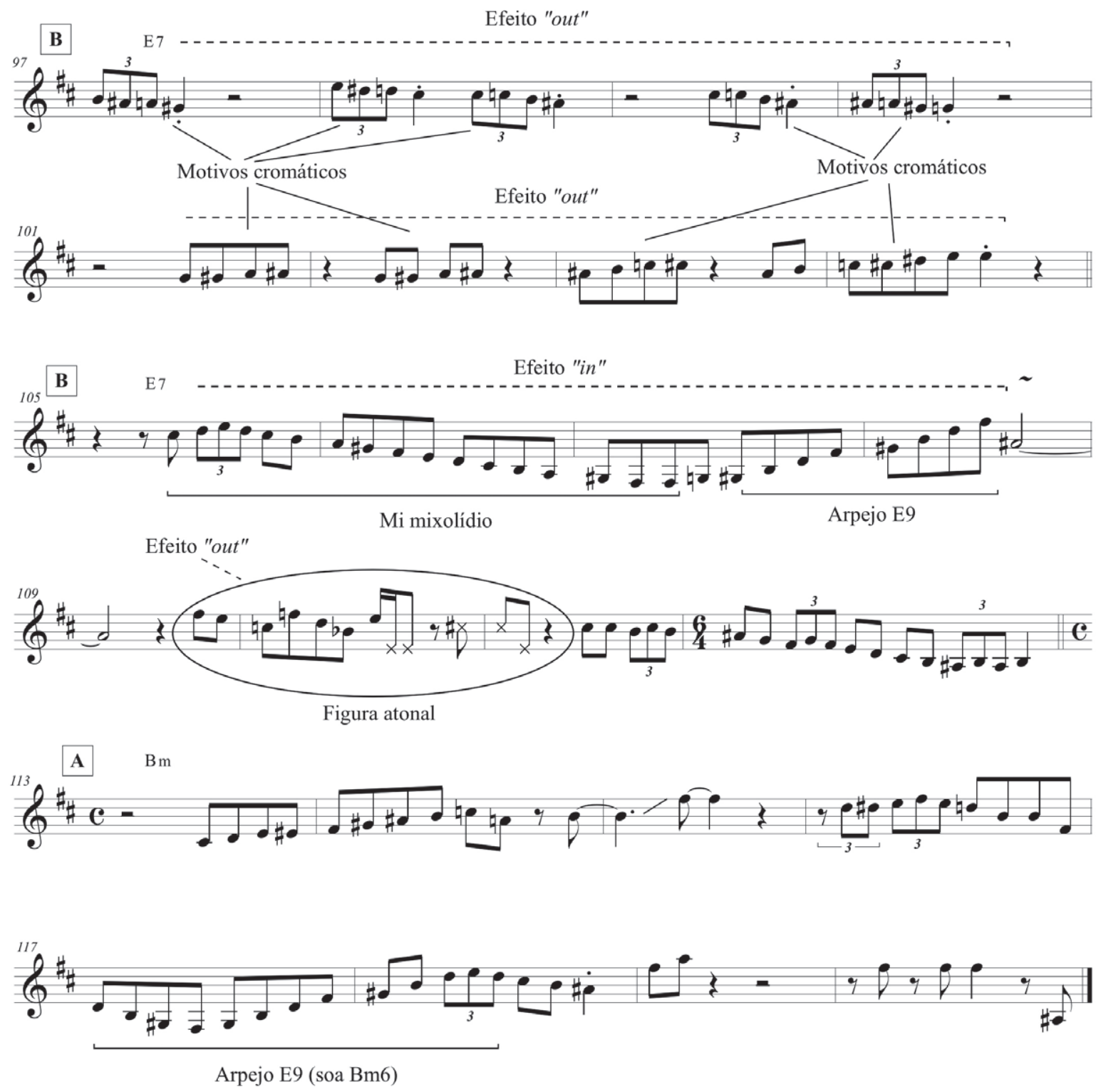

Ex.7 - Segundo chorus do solo de Django em Flèche d'Or, Seção B, c.97-104.
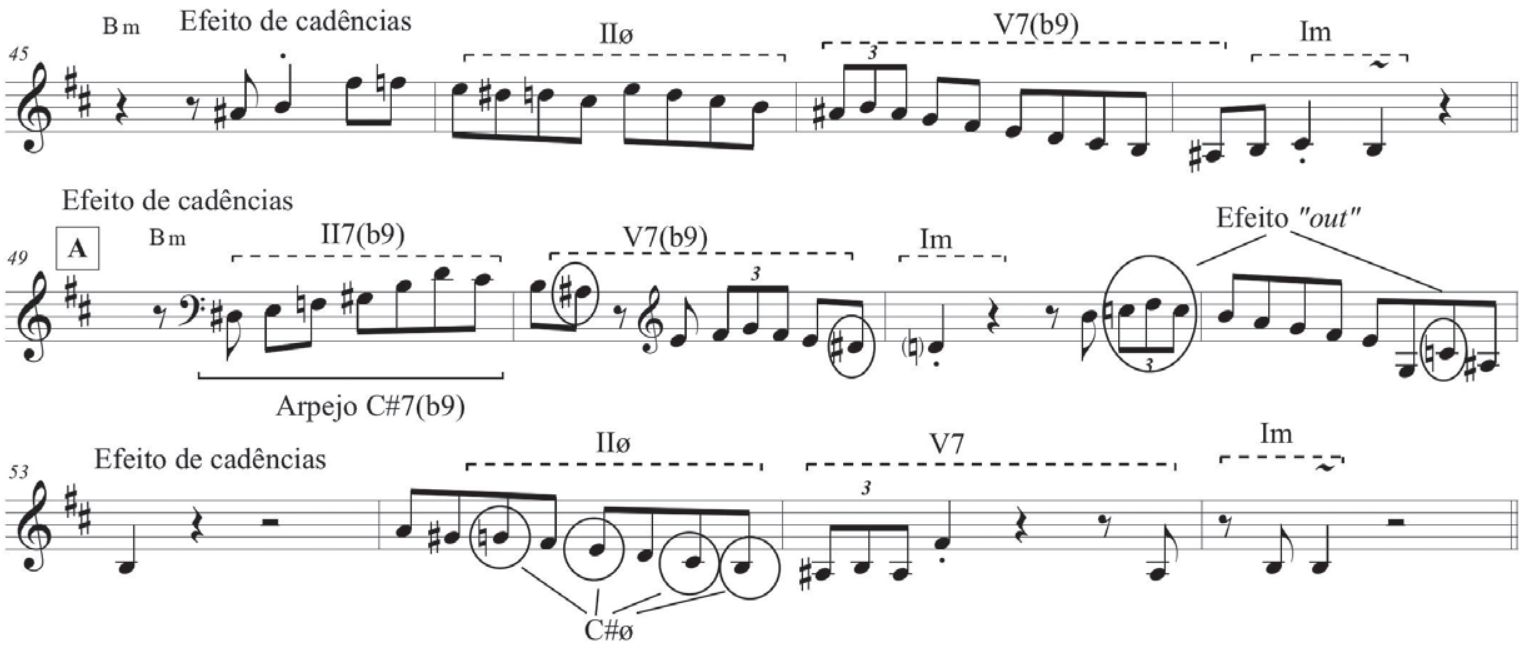

Ex.8 - Efeito de cadências no solo de Django em Flèche d'Or, chorus 1, Seção A, c.45-56. 
A Bm Efeito " $i n$ " rítmico
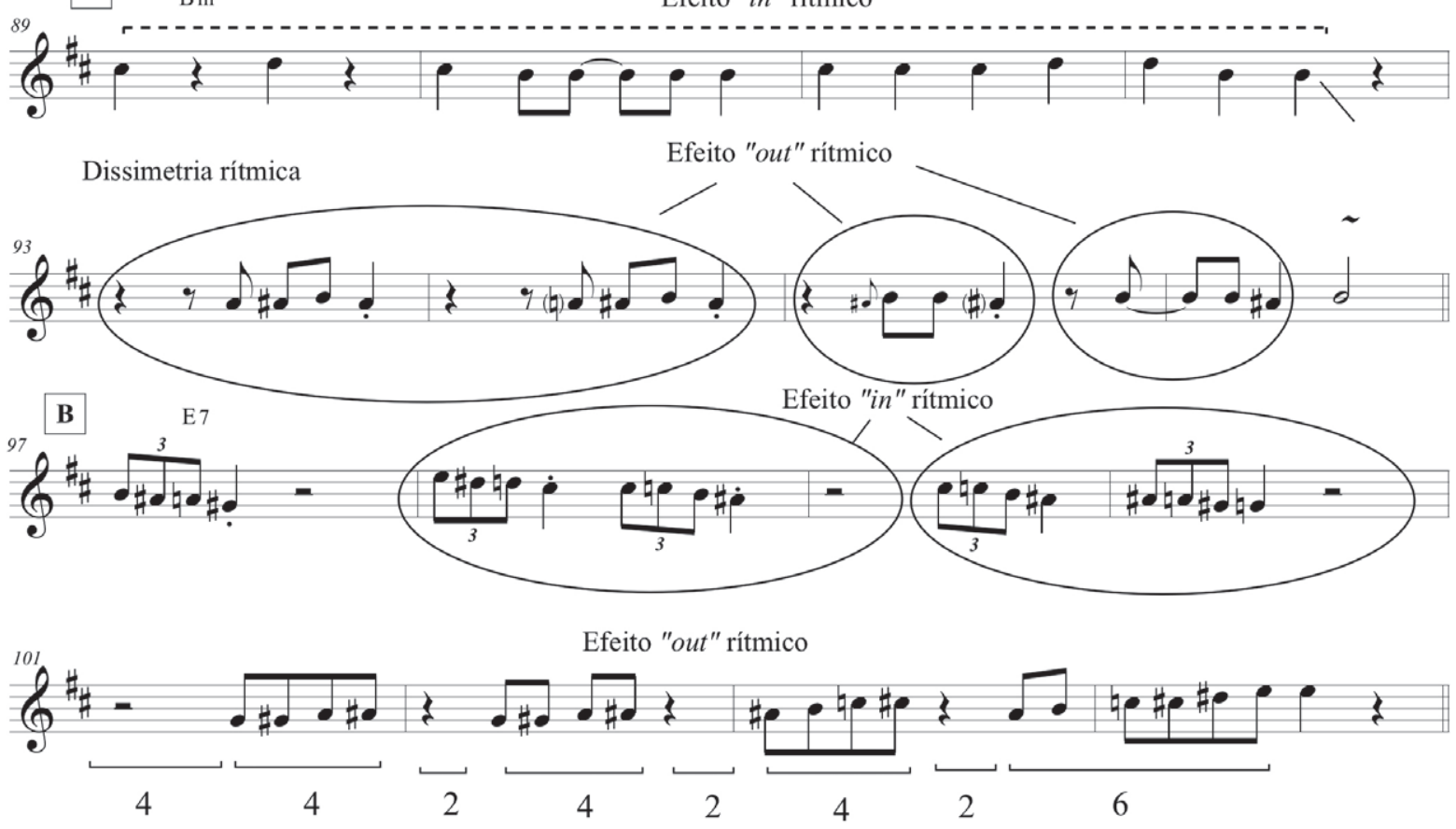

Ex.9 - Efeito de dissimetria rítmica e alternância de frases "in" e "out" ritmicamente no solo de Django em Flèche d'Or, chorus 2, c.89-104.

\section{Referências de partitura}

REINHARDT, Django; CUGNY, Laurent. Flèche d'or. partitura transcrita e editada por Laurent Cugny a partir da gravação do compositor no disco Django Reinhardt e sua orquestra (1952). "Le solo de Django Reinhardt dans Fléche d'Or" in: Les Cahiers du jazz, nouvelle série, n³, 2006, p.213-218.

\section{Referências de Gravações}

DAVIS, Miles. Kind of blue. Columbia: CS 8163,1959. (LP) Milestones. Columbia: CL 1193, 1958. (LP)

REINHARDT, Django. Flèche d'Or. In: Intégrale Django Reinhart v.12 Troublant Boléro - 1950-1952. Frémeaux \& Associés:

FA 319 (CD2, faixa 12), 2004. (gravação original de 30 jan. 1952, Decca, Paris).

MCFARLAND, Gary; MULLIGAN, Gerry. Bridgehampton Strut. In: Mulligan '63, The Concert Jazz Band, 1963.

CALDERAZZO, Joey; BRECKER, Michael. Midnight Voyage. In: Tales from the Hudson, Impulse Records, 1996. 


\section{Notas}

1 Lembramos que já em 1927, Jelly Roll Morton teria composto e gravado Jungle Blues que permanence sobre apenas um acorde. Os seis primeiros compassos da seção A de Caravan de Duke Ellington pode de um certo ponto de vista, ser igualmente considerado como modal.

2 Esta interpretação supõe certamente que a gravação chegou a nós não tenha sido objeto de uma montagem em pós-produção. Esta hipótese me parece, de qualquer forma, muito improvável, não somente devido à data relativamente remota em termos de tecnologia de gravação mas, sobretudo, devido ao que se percebe pela escuta.

3 Cf. partitura do tema, publicada nesta edição de Per Musi, p.21-23.

4 Também o seria para Milestones e Kind of Blue, mas isto é outra história.

5 No texto, o nome usado é "ringard", como trocadilho com o sobrenome de Django, Reinhardt. (Nota do tradutor).

Laurent Cugny, pianista, arranjador e maestro, músico autodidata. Fundou a big band Lumière em 1979 e começou a gravar com esta orquestra a partir de 1981. Em 1987, toca e grava com Gil Evans, e de 1994 a 1997 dirige a Orquestra Nacional de Jazz. Trabalha também como arranjador, notadamente para Abbey Lincoln, Lucky Peterson, Juliette Gréco, David Linx, Ricardo Tepperman. Em 2006, criou no Festival Jazz à Vienne, a ópera-jazz La Tectonique des nuages que fora reapresentada no ano seguinte no Théatre de la Ville em Paris, e gravado em 2009 pelo selo Signature (Radio France). Neste mesmo ano, reformou a Enormous Band de vinte e três músicos que se apresentou nos Festivais de Vienne e de Marciac, e na Cité de la Musique. Em 2001, defendeu a tese de doutorado L'analyse de l'œuvre de jazz: spécificités théoriques et méthodologiques na Universidade Paris-Sorbonne (Paris IV), e em 2004, passou a coordenar pesquisas sobre História do jazz e Teoria do jazz. Professor Titular da Universidade Paris-Sorbonne desde 2006, Cugny é autor dos livros Las Vegas Tango: Une vie de Gil Evans (P.0.L., 1989, traduzido em japonês em 1996), Électrique: Miles davis 1968-1975 (André Dimanche, 1993, reedição Tractatus \& Co, 1009), Analyser le jazz (Outre Mesure, 2009). Coordena e é autor de uma coletânea sobre a história do jazz na França, patrocinada pela Agência Nacional da Pesquisa e pela Sacem.

Fabiano Araújo, pianista e compositor, desenvolve tese de doutorado sobre o jazz contemporâneo, desde 2012, na Universidade Paris-Sorbonne (Paris-IV), com bolsa CAPES, junto ao grupo JCMP-OMF (Jazz, chanson et musiques populaires - Observatoire Musical Français). É Mestre em Música pela Escola de Música da UFMG e Bacharel em Música Popular pelo Centro de Artes da UNICAMP. É Professor Assistente do Centro de Artes da Universidade Federal do Espírito Santo (UFES), onde contribuiu para a criação o curso de Bacharelado em Música, habilitação em Composição com ênfase em Trilha Musical. Lançou 4 CDs: 0 Aleph (2007); Calendário do Som - 9 dias (2009) de Hermeto Pascoal, gravado e publicado em Portugal, com a participação do contrabaixista norueguês Arild Andersen do baterista Alexandre Frazão (Brasil/Portugal) e do saxofonista Guto Lucena (Brasil/Portugal); Rheomusi (2011) em trio com Arild Andersen e Naná Vasconcelos, e Baobab trio (2012), com peças de Radamés Gnattali, Baden Powell além de música improvisada em trio. 